\title{
Height adjustment reduces occurrence of low bone mineral density in children and adolescents with HIV
}

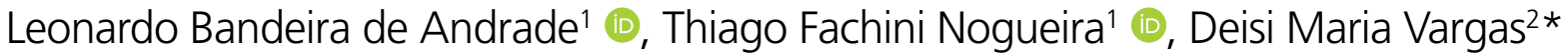

\section{SUMMARY}

OBJECTIVE: The aim of this study was to quantify the reduction of bone mineral density with and without height adjustment. METHODS: A cross-sectional study was performed with 69 Brazilian children and adolescents vertically infected by HIV. Bone mineral density was measured by dual-energy absorptiometry in the lumbar spine. Anthropometric, demographic, and clinical variables were analyzed. A specific calculator was used for height adjustment.

RESULTS: The majority of participants (52.2\%) were adolescents and did not present with immunological alterations (61\%). Reduced bone mineral density ( $Z$-score $<-1$ ) was present in $23.2 \%$ and low bone mass ( $Z$-score $<-2$ ) in $5.8 \%$. After height adjustment, these occurrences decreased to $11.6 \%$ and $0 \%$, respectively. Patients with reduced bone mineral density had a higher mean age and lower body mass index than patients with normal bone mineral density.

CONCLUSION: The occurrence of reduced bone mineral density decreased after adjustment for height.

KEYWORDS: Bone mineral density. HIV. Child. Adolescent. Osteoporosis.

\section{INTRODUCTION}

Chronic diseases, such as acquired immunodeficiency virus (HIV) infection, are the main causes of reduced bone mass (BM) during childhood and adolescence ${ }^{1-3}$. Each chronic disease may alter bone metabolism in a specific way, depending on the system affected and associated morbidities and interventions, which may affect BM in different ways and magnitudes ${ }^{1}$. Children and adolescents with HIV are at higher risk for BM loss ${ }^{2-4}$.

Although the mechanisms of this loss are not fully understood, monitoring bone health is part of the care of people with $\mathrm{HIV}^{5,6}$. Alterations in bone metabolism, nutrient deficiency, and the use of antiviral therapy (ATV), especially protease inhibitors (PIs), have been associated with reduced $\mathrm{BM}^{2,7-9}$. With the improvement of ATV and greater ease of access, children with HIV have reached adolescence and adulthood with an increased risk of BM loss due to increased exposure to risk factors throughout life $\mathrm{e}^{10-12}$.

Dual-energy densitometry (DXA) is the method of choice for evaluating BM in children and adolescents by quantifying bone mineral density (BMD) ${ }^{1}$. Its main limitation is the quantification of areal BMD (aBMD). By not measuring volumetric $\mathrm{BMD}, \mathrm{BM}$ measured by DXA is influenced by bone size, thereby underestimating $\mathrm{BM}$ in smaller people and generating false-positive results for low $\mathrm{BM}^{13,14}$.

\footnotetext{
${ }^{1}$ Universidade de Blumenau, Centro de Ciências de Saúde, Departamento de Medicina - Blumenau (SC), Brazil.

2Universidade de Blumenau, Centro de Ciências de Saúde, Departamento de Medicina e Programa de Pós-graduação em Saúde Coletiva - Blumenau (SC), Brazil.

*Corresponding author: deisifurb@gmail.com

Conflicts of interest: the authors declare there are no conflicts of interest. Funding: Programa de Iniciação Científica, Conselho Nacional de Desenvolvimento Científico e Tecnológico (PIBIC/CNPq).

Received on June 21, 2021. Accepted on July 13, 2021.
} 
Considering that growth deficit is a frequent situation in children and adolescents with $\mathrm{HIV}^{5}$, the evaluation of BM by DXA may overestimate the occurrence of low BM. Despite this, most studies on the evaluation of BM by DXA in children and adolescents with HIV did not perform adjustments to minimize the impact of bone size on DXA results. One possible strategy for this purpose is to adjust for height, generating aBMD adjusted for height $\left(\mathrm{aBMD}_{\mathrm{HAZ}}\right)^{15}$. Thus, this study aimed to evaluate BMD by DXA in pediatric patients with HIV, quantifying the occurrence of BMD reduction with and without adjustment for height and analyzing associated factors.

\section{METHODS}

\section{Study design and participants}

This is a cross-sectional study conducted on HIV carriers followed up in the Unified Health System. The inclusion criteria were children and adolescents with vertical HIV who had undergone bone densitometry in the lumbar spine. Incomplete clinical data, and age below 5 years, due to the technical limitations of height adjustment, were considered exclusion criteria. Data collection occurred between February and May 2018.

\section{Sociodemographic variables}

Age and Sex. Age was categorized into school age (5-10 years) and adolescent age (11-19 years).

\section{Densitometric variables}

Areal BMD $\left(\mathrm{g} / \mathrm{cm}^{2}\right)$ in the lumbar spine (L1-L4) was performed with DXA Explorer model equipment (Hollogic Inc., Bedford, MA, USA) and transformed into $Z$-score for sex and age by the equipment software (Apex, version 2.1). Subsequently, using the Pediatric Bone Density Calculator tool (available at https://zscore.research.chop.edu/calcpedbonedens.php), the $Z$-score of height for age was adjusted, generating aBMD ${ }_{\text {HAZ }}$. Low BMD was considered a $Z$-score $\leq-2^{16}$ and reduced BMD a $Z$-score $<-1^{17}$.

\section{Anthropometric variables}

Weight, height, and body mass index (BMI) were transformed into $Z$-scores for age using a calculator (available at https://www. bcm.edu/bodycomplab/Flashapps/AllDXArefsChartpage.html).

\section{Clinical variables}

These categories include viral load (CV), CD4 and CD8 counts, the use of ATV, the use of PI, and clinical category according to the Centers for Disease Control and Prevention (CDC). CD4 was categorized according to the $\mathrm{CDC}^{18}$ in children under 12 years of age and according to the World Health Organization ${ }^{19}$ in older patients. CD4 and CD8 were dosed by flow cytometry.

\section{Statistical analysis}

Kolmogorov-Smirnov, Student's $t$, ANOVA, chi-square, and simple and multiple linear regression tests were used. All variables were presented in terms of a parametric distribution. Variables with $\mathrm{p} \leq 0.2$ in the simple regression were included in the multiple regression. A two-tailed sample power for the comparison of means was calculated, with an alpha error of $5 \%$. The study was approved by the Research Ethics Committee of the University of Blumenau (opinion 020-04).

\section{RESULTS}

The study included 69 out of a total of 96 children and adolescents with vertical HIV followed up in the service. Exclusions were due to age $<5$ years $(n=12)$ and incomplete data $(n=15)$. Table 1 presents the characteristics of the participants. An occurrence of $23.2 \%$ of reduced BMD and $5.8 \%$ of low BM was observed. With the $\mathrm{aBMD}_{\mathrm{HAZ}}$ calculation, the occurrence of reduced $\mathrm{BMD}$ was $11.6 \%$, half of that found with aBMD (chi-square $=29.97 ; \mathrm{p}<0.00001$ ), and the occurrence of low BMD was $0 \%$.

Patients with reduced BMD had higher age and lower BMI. These differences remained after adjustment for height (Table 2). Adolescents $(\mathrm{n}=36)$ had lower $\mathrm{aBMD}$ and $\mathrm{aBMD} \mathrm{HAZ}_{\mathrm{H}}$ than those of schoolchildren $(-0.72 \pm 1.3$ vs. $0.18 \pm 1.0 ; \mathrm{p}<0.005$ and $-0.09 \pm 0.98$ vs. $0.76 \pm 1.0 ; \mathrm{p}<0.05$; power of test $>90 \%$ ) and higher aBMD in $\mathrm{g} / \mathrm{cm}^{2}(0.741 \pm 0.168$ vs. $0.551 \pm 0.071$; $\mathrm{p}<0.0005$; power of test $>90 \%$ ).

We observed a trend of progressive reduction of BM in association with clinical worsening that was less evident after adjustment for height, which reduced progressively throughout the clinical categories (ANOVA $\mathrm{p}<0.05$; power of test $<80 \%$ ) (Figure 1).

Both aBMD and $\mathrm{aBMD}_{\mathrm{HAZ}}$ correlated negatively with BMI and age $(\mathrm{r}=-0.39, \mathrm{p}<0.001$ and $\mathrm{r}=-0.37, \mathrm{p}<0.01$ respectively $)$ and positively with $\mathrm{CV}(\mathrm{r}=0.32, \mathrm{p}<0.01$ and $\mathrm{r}=0.44, \mathrm{p}<0.001)$, and $\mathrm{aBMD}$ correlated positively with height $(\mathrm{r}=0.32, \mathrm{p}<0.01)$. In multiple linear regression, we observed a positive and independent correlation of aBMD with $\mathrm{CV}$ and $\mathrm{BMI}\left(\mathrm{R}^{2}\right.$ adjusted $0.21 ; \mathrm{S}=1.15 ; \mathrm{F}=9.19 ; \mathrm{p}<0.0005)$.

\section{DISCUSSION}

The adjustment for height minimized the occurrence of BM loss, demonstrating the impact of growth on the quantification of BM by DXA. The magnitude of this reduction is 
Table 1. Characteristics of the participants.

\begin{tabular}{|c|c|c|c|c|}
\hline Numerical Variables & Mean \pm SD & $95 \% \mathrm{Cl}$ & Minimum & Maximum \\
\hline Age (years) & $1.5 \pm 3.6$ & 9.6 to 11.3 & 5.0 & 18.5 \\
\hline Use of ATV (months) & $41.1 \pm 31.3$ & 33.2 to 49.1 & 0.0 & 197.0 \\
\hline CD4 (cells $/ \mathrm{mm}^{3}$ ) & $757.8 \pm 429.0$ & 654.8 to 860.9 & 47.0 & $2,177.0$ \\
\hline BMI (Z-score) & $-0.4 \pm 1.1$ & -0.7 to -0.2 & -4.4 & 1.6 \\
\hline Weight (Z-score) & $-0.8 \pm 1.1$ & -1.1 to -0.6 & -3.3 & 1.6 \\
\hline Height (Z-score) & $-0.9 \pm 0.9$ & -1.1 to -0.7 & -2.9 & 1.1 \\
\hline $\mathrm{BMD}(\mathrm{g})$ & $0.6 \pm 0.2$ & 0.6 to 0.7 & 0.1 & 1.2 \\
\hline BMD (Z-score) & $-0.3 \pm 1.3$ & -0.6 to 0.0 & -4.1 & 3.2 \\
\hline Height adjusted BMD (Z-score) & $0.3 \pm 1.1$ & 0.1 to 0.6 & -1.8 & 3.5 \\
\hline CD8 (cells $\left./ \mathrm{mm}^{3}\right)$ & $1,346.7 \pm 667.3$ & $1,181.3$ to $1,521.0$ & 317.0 & $3,642.0$ \\
\hline Viral load (copies/mL) & $35,196.2 \pm 74,883.0$ & $16,179.4$ to $52,212.9$ & 0 & $39,000.0$ \\
\hline Categorical Variables & \multicolumn{2}{|c|}{ Frequency (n) } & \multicolumn{2}{|c|}{ Relative Frequency (\%) } \\
\hline \multicolumn{5}{|l|}{ Sex } \\
\hline Male & \multicolumn{2}{|c|}{33} & \multicolumn{2}{|c|}{47.8} \\
\hline Female & \multicolumn{2}{|c|}{36} & \multicolumn{2}{|c|}{52.2} \\
\hline \multicolumn{5}{|l|}{ Age } \\
\hline Adolescent age & \multicolumn{2}{|c|}{36} & \multicolumn{2}{|c|}{52.2} \\
\hline School age & \multicolumn{2}{|c|}{33} & \multicolumn{2}{|c|}{47.8} \\
\hline \multicolumn{5}{|l|}{ Immunologic category } \\
\hline None or mild suppression & \multicolumn{2}{|c|}{42} & \multicolumn{2}{|c|}{60.8} \\
\hline Moderate suppression & \multicolumn{2}{|c|}{23} & \multicolumn{2}{|c|}{33.4} \\
\hline Severe suppression & \multicolumn{2}{|r|}{4} & \multicolumn{2}{|c|}{5.8} \\
\hline \multicolumn{5}{|l|}{ Reduced BMD (Z-score <-1) } \\
\hline Yes & \multicolumn{2}{|c|}{16} & \multicolumn{2}{|c|}{23.2} \\
\hline No & \multicolumn{2}{|c|}{53} & \multicolumn{2}{|c|}{76.8} \\
\hline \multicolumn{5}{|l|}{ Low BMD (Z-score <-2) } \\
\hline Yes & \multicolumn{2}{|r|}{4} & \multicolumn{2}{|c|}{5.6} \\
\hline No & & 65 & & \\
\hline Clinical categorya & & & & \\
\hline $\mathrm{N}$ & & 4 & & \\
\hline A & & 19 & & \\
\hline $\mathrm{B}$ & & 34 & & \\
\hline C & & 8 & & \\
\hline Use of ATV & & & & \\
\hline Yes & & 68 & & \\
\hline No & & 1 & & \\
\hline Use of protease inhibitors & & & & \\
\hline Yes & & 46 & & \\
\hline No & & 19 & & \\
\hline
\end{tabular}

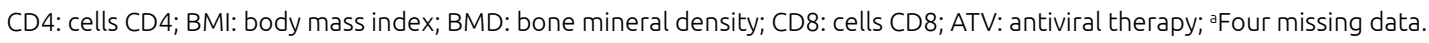


Table 2. Clinical characteristics of the participants according to the bone mineral density status with and without height adjustment.

\begin{tabular}{|c|c|c|c|c|c|c|}
\hline \multirow{2}{*}{ Variables } & \multirow{2}{*}{$\begin{array}{c}\text { Reduced aBMD } \\
(\mathrm{n}=16) \\
\text { Mean } \pm \text { SD/ } \\
n(\%)\end{array}$} & \multicolumn{2}{|c|}{$\begin{array}{c}\text { Normal aBMD } \\
(n=53)\end{array}$} & \multirow{2}{*}{$\begin{array}{c}\text { Reduced aBMD } \\
(\mathrm{n}=8) \\
\text { Mea } \\
\text { Meas } \pm \text { S } \\
n(\%)\end{array}$} & \multicolumn{2}{|c|}{$\begin{array}{c}\text { Normal aBMD } \\
(n=61)\end{array}$} \\
\hline & & $\begin{array}{l}\text { Mean } \pm \text { SD/ } \\
\mathrm{n}(\%)\end{array}$ & p-value & & $\begin{array}{c}\text { Mean } \pm \text { SD/ } \\
n(\%)\end{array}$ & $p$-value \\
\hline Age (years) & $13.5 \pm 2.9$ & $9.5 \pm 3.5$ & $<0.001^{\mathrm{a}}$ & $13.4 \pm 3.7$ & $10.1 \pm 3.6$ & $<0.001^{a}$ \\
\hline Use of ATV (months) & $51.6 \pm 28.5$ & $37.8 \pm 31.6$ & $\mathrm{NS}^{\mathrm{a}}$ & $32.5 \pm 19.9$ & $42.5 \pm 32.5$ & $N S^{a}$ \\
\hline CD4 (cells/mm³) & $616.8 \pm 575.8$ & $800.3 \pm 370.2$ & $N S^{a}$ & $569.1 \pm 514.8$ & $779.9 \pm 416.4$ & $N S^{a}$ \\
\hline CD8 (cells/mm³) & $1,252.7 \pm 614.4$ & $1,374.8 \pm 685.7$ & $N S^{a}$ & $1,247.0 \pm 802.6$ & $1,360.6 \pm 653.2$ & NS \\
\hline BMI (Z-score) & $-1.0 \pm 1.5$ & $0.3 \pm 0.9$ & $<0.05^{a}$ & $-1.0 \pm 1.6$ & $-0.4 \pm-1.0$ & $<0.05^{a}$ \\
\hline Height (Z-score) & $-0.8 \pm 0.9$ & $-1.3 \pm 0.8$ & $N S^{a}$ & $-1.1 \pm 0.9$ & $-0.9 \pm 0.9$ & $N S^{a}$ \\
\hline Use of protease inhibitor & $9(19.6)$ & $37(80.4)$ & $N S^{b}$ & $4(8.7)$ & $42(91.3)$ & $N S^{b}$ \\
\hline
\end{tabular}

aBMD: bone mineral density without height adjustment; aBMD $_{\text {HAz }}$ bone mineral density with height adjustment; ATV: antiviral therapy; BMI: body mass index; aStudent's t-test (power of test $>75 \%$ for age, body mass index, and height, and $<75 \%$ for the use of antiviral therapy, cells CD4, and cells

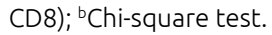

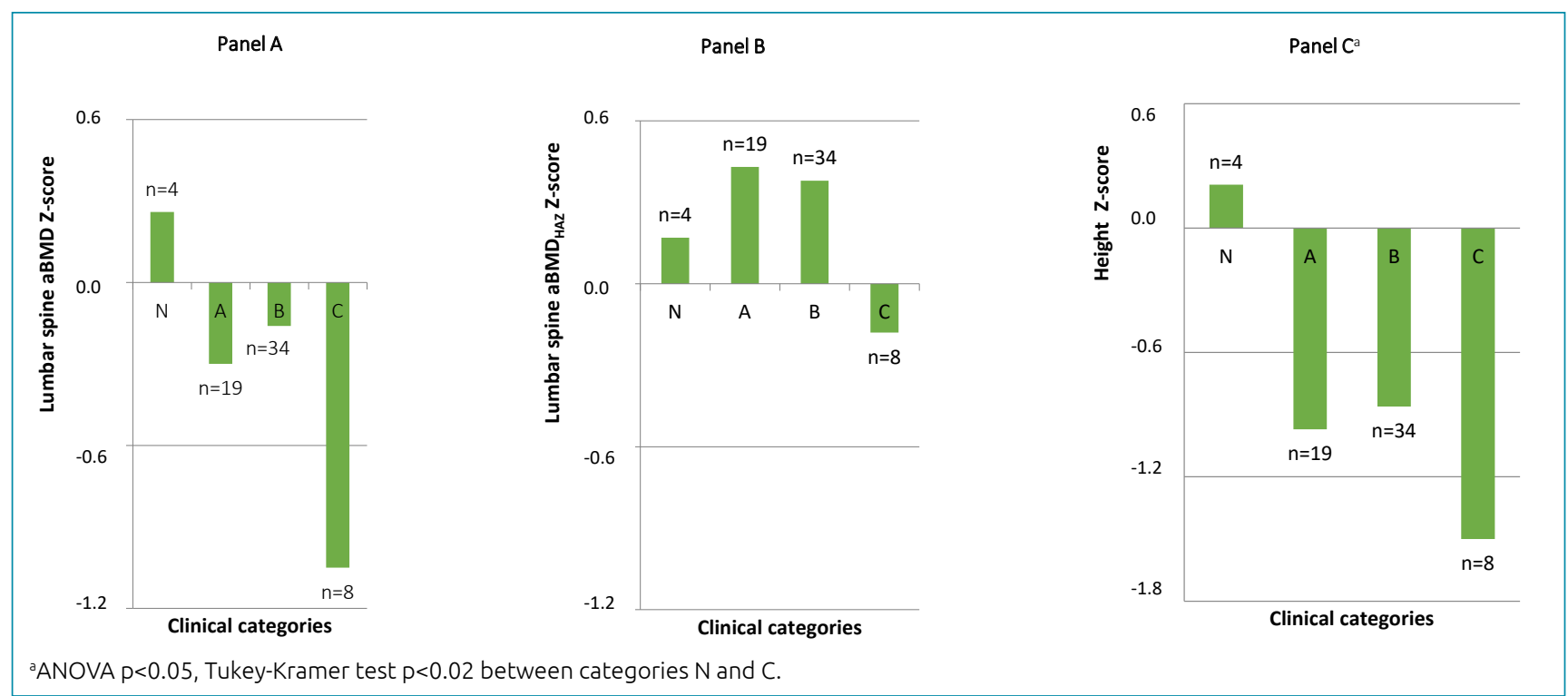

Figure 1. Bone mineral density without and with height adjustment (Panel $A$ and $B$ respectively) and height (Panel $C$ ) according to clinical categories.

relevant. While one-fourth of the participants presented with reduced BMD, only one-tenth remained with this diagnosis after adjustment, showing a reduction of over $50 \%$. The same was observed in relation to low BM, whose occurrence disappeared with the adjustment. To date, Jimenez et al. ${ }^{3}$ were the only authors who adjusted BMD for height, showing a significant reduction in the occurrence of low BMD (from 15.3\% to $4.1 \%)$. By adjusting aBMD to volumetric BMD using a mathematical formula, Sudjaritruk et al. ${ }^{20}$ also observed a $50 \%$ reduction in the occurrence of low BMD in the lumbar spine (from $16.4 \%$ to $8.3 \%$ ). Therefore, the correction for bone size from two different strategies improves the accuracy of DXA in children and adolescents with HIV.

The lower occurrence of decreased BMD generated by adjusting for height is explained by the two-dimensional nature of DXA. This characteristic of the technique underestimates 
BMD in small bones, leading to a lack of diagnostic accuracy in short people by not considering bone volume ${ }^{13,14}$. Because of the conditions associated with HIV infection throughout the course of the disease, children and adolescents with HIV have a higher prevalence of short stature ${ }^{2,9}$, thus adjusting for height avoids false-positive diagnoses of BM reduction.

Approximately one-fourth of the patients had reduced BMD in the lumbar spine and 5.8\% had low BM. The occurrences were 21,34 , and $42 \%{ }^{9,21,22}$ for reduced BMD and 4,11 , $15 \%, 16 \%$, and $32 \%$ for low $\mathrm{BMD}^{2,3,9,21,23}$ have been reported. This variability is related to the profiles involved, especially age and clinical category. Studies with older participants ${ }^{2,22}$ or those with a predominance of category $\mathrm{C}^{2,9}$ showed higher rates of impaired BM. When greater age and a predominance of category $\mathrm{C}$ are associated, the occurrence of low $\mathrm{BM}$ reaches $32 \%{ }^{2}$. The occurrences observed in this study are similar to an American study with a similar clinical profile ${ }^{21}$.

The clinical variables that were associated with BMD were age, age group, and BMI. Although studies have shown an association between BM and the use of ATV ${ }^{9,20,21}$ such as duration and class, this association was not evidenced in this study. PI was used with most participants, which limited the analysis of its effect on BM. BMD showed a negative correlation with age, as observed recently ${ }^{20,22}$. Pubertal delay and disease chronicity justify this association. Adolescents with HIV initiate puberty later, delaying the accelerated BM gain characteristic of puberty ${ }^{24}$; and older participants have a longer period of exposure to the disease and, therefore, are more exposed to the deleterious effects of the disease. Longitudinal data show that adolescents with vertical HIV have lower BM acquisition during puberty compared to HIV-negative adolescents ${ }^{4}$. Participants with reduced BMD were thinner and older, a difference that was maintained after adjustment for height. Low weight, more prevalent in children and adolescents with vertical HIV, is associated with lower BMD and related to disease chronicity ${ }^{20-22}$. The compromised nutritional status and the chronicity of the disease seem to negatively impact the acquisition of BM in children and adolescents with vertical HIV.

The pathophysiology of bone loss in children and adolescents with HIV is complex and multifactorial. Different mechanisms seem to act on the activity and response of bone cells depending on the clinical conditions, treatments received, and the life cycle of the affected person ${ }^{8}$. While some studies show an increase in bone remodeling, others show the opposite result. These studies differ in terms of the profile of the participants evaluated. Low bone remodeling is described in children under prepubertal majority, with analysis of markers of bone formation and resorption adjusted for age and sex, compared to a control group ${ }^{23}$. High bone remodeling is described in older, mostly pubertal participants with analyses of markers of bone formation and resorption without adjustment for sex, age, or pubertal stage $e^{20}$. Bone metabolism markers vary throughout childhood and adolescence, being highest during puberty ${ }^{25}$. The high bone remodeling observed in the older, mostly pubescent group, probably reflects this physiological moment. In a longitudinal evaluation, BMD increases progressively with age, but at a lower magnitude than in children and adolescents without HIV, such that by age 18 , aBMD and volumetric BMD are $\mathrm{low}^{20}$. Considering that there is no BM loss but insufficient gain, low bone remodeling seems to be the most plausible pathophysiological mechanism. This phenomenon is observed indirectly in this study, since the adolescents had a lower BMD Z-score and a higher $\mathrm{BMD} \mathrm{g} / \mathrm{cm}^{2}$ than the schoolchildren.

This study is the first national study and the second at the international level to demonstrate the limitation of the DXA technique in the evaluation of BMD in children and adolescents with HIV, when interpreted without adjustment for height. We recommend adjusting BMD for height in the evaluation of BM by DXA in children and adolescents with HIV to avoid the diagnostic inaccuracy inherent to this technique. In order to know more precisely the evolution of BMD assessed by DXA throughout childhood and adolescence in this clinical condition, it would be of great interest that ongoing longitudinal studies incorporate the adjustment of BMD for height in their study protocol.

The limitations of this study include data transversality, which limits the establishment of a cause-and-effect relationship; the nonprobability sample, which does not guarantee the representativeness of the population of children and adolescents with vertical HIV; and the reduced number of participants in clinical categories $\mathrm{N}$ and $\mathrm{C}$, which limited the analysis of $\mathrm{BMD}$ variations between clinical categories.

\section{CONCLUSIONS}

Adjustment for height reduced the occurrence of reduced BMD and low BM in the lumbar spine of children and adolescents with vertical HIV, indicating its relevance in the evaluation of BM by DXA in order to avoid false-positive diagnoses of BM loss. Reduced BMD was associated with greater age and lower BMI.

\section{AUTHORS" CONTRIBUTIONS}

LBA, TFN: Conceptualization, Data curation, Formal analyses, Writing - original draft. DMV: Conceptualization, Funding acquisition, Project administration, Formal analyses, supervision, Writing - original draft, Writing - review \& editing. 


\section{REFERENCES}

1. Bachrach LK, Gordon CM. Bone densitometry in children and adolescents. Pediatr. 2016;138(4):e20162398. https://doi.org/ 10.1542/peds.2016-2398.

2. Schtscherbyna A, Pinheiro MFMC, Mendonça LMC, Gouveia C, Luiz RR, Machado ES, et al. Factors associated with low bone mineral density in a Brazilian cohort of vertically HIV-infected adolescents. Int J Infect Dis. 2012;16(12):e872-e8.

3. Jiménez B, Sainz T, Díaz L, Mellado MJ, Navarro ML, Rojo $P$, et al. Low bone mineral density in vertically HIV-infected children and adolescents: risk factors and the role of t-cell activation and senescence. Pediatr Infect Dis J. 2017;36:(6)57883. https://doi.org/10.1097/INF.0000000000001506.

4. Mahtab S, Scott C, Asafu-Agyei NAA, Machemedze T, Frigati L, Myer $L$, et al. Prevalence and predictors of bone health among perinatally HIV-infected adolescents. AIDS. 2020; 34(14):206170. https://doi.org/10.1097/QAD.0000000000002686.

5. Cruz MLS, Cardoso CA. Perinatally infected adolescents living with human immunodeficiency virus (perinatally human immunodeficiency virus). World J Virol. 2015;4(3):277-84. https://doi.org/10.5501/wjv.v4.i3.277.

6. Innes S., Patel K. Noncommunicable diseases in adolescents with perinatally-acquired HIV-1 infection in high-income and low-income settings. Curr Opinion HIVIAIDS. 2018;13(3):187-95.

7. Yin MT, Brown TT. HIV and bone complications: understudied populations and new management strategies. Curr HIVIAIDS Rep. 2016;13(6):349-58. https://doi.org/10.1007/s11904016-0341-9.

8. Ahmad AN, Ahmad SN, Ahmad N. HIV infection and bone abnormalities. Open Orthop J. 2017;11:777-84. https://doi. org/10.2174/1874325001711010777.

9. Torrejón C, Galaz MI, Vizueta E, Álvarez AM, Wu E, Chávez $A$, et al. Evaluación de la densidad mineral ósea en niños con infección vertical por VIH. Rev Chil Infectol. 2018;35(6):63441. https://doi.org/10.4067/S0716-10182018000600634.

10. Patel K, Hernán MA, Williams PL, Seeger JD, Mclntosh K, Van Dyke RB, et al. Long-term effectiveness of highly active antiretroviral therapy on the survival of children and adolescents with HIV infection:10-year follow-up study. Clin Infect Dis. 2008;46(4):507-15.

11. Cezarino PYA, Simões RS, Baracat EC, Soares Junior JM. Are women living with HIV prone to osteoporosis in postmenopause? A systematic review. Rev Assoc Med Bras. 2018;64(5):469-73. https://doi.org/10.1590/1806-9282.64.05.469.

12. Vreeman RC, Scanlon ML, McHenry MS, Nyandiko WM. The physical and psychological effects of HIV infection and its treatment on perinatally HIV-infected children. J Int AIDS Soc. 2015;18(suppl. 6):20258. https://doi.org/10.7448/ IAS.18.7.20258

13. Schoenau E, Land C, Stabrey A, Remer T, Kroke A. The bone mass concept: problems in short stature. Eur J Endocrinol. 2004;151(Suppl 1):S87-S91.

14. Floroskoufi P, Daraki V, Stratakis J, Kalikakis G. Papavasiliou S. Overdiagnosis of osteoporosis in a patient with short stature and partial growth hormone insensitivity due to misinterpretation of dual-energy X-ray absorptiometry (DEXA). Endocrine Abstracts. 2016; 41:EP331. https://doi.org/10.1530/ endoabs.41.EP331.

15. Kindler JM, Lappe JM, Gilsanz V, Oberfield S, Shepherd JA, Kelly $A$, et al. Lumbar spine bone mineral apparent density in children: results from the bone mineral density in childhood study. J Clin Endocrinol Metab. 2019 104(4):1283-92. https:// doi.org/10.1210/jc.2018-01693.

16. International Society for Clinical Densitometry. Official Positions Pediatric [Internet]. Middletown: ISCD; 2019. p. 34-46 [cited on July 16 2020]. Available from: https://iscd.app.box.com/s/ ae9gusunsr6e0fmxkqxosaczmnuhujx4.

17. Zemel BS, Petit M. Evaluation. In: Sawyer AJ, Bachrach LK, Fung EB. Bone densitometry in growing patients: guidelines for clinical practice. Totowa: Humana Press; 2007. p. 115-25.

18. Centers for Disease Control and Prevention. Revised. Classification system of human immunodeficiency virus infection in children less than 13 years of age. Morbidity Mortality Weekly Report. September 30, 1994;43(RR-12):1-10.

19. World Health Organization. WHO case definitions of HIV for surveillance and revised clinical staging and immunological classification of HIV-related disease in adults and children [Internet]. Geneva: World Health Organization; 2007. [cited on Dec. 16 2018]. Available from: www.who.int/hiv/pub/ guidelines/HIVstaging150307.pdf.

20. Sudjaritruk T, Bunupuradah T, Aurpibul L, Kosalaraksa $\mathrm{P}_{\mathbf{t}}$ Kurniati N, Prasitsuebsai W, et al. Adverse bone health and abnormal bone turnover among perinatally HIV-infected Asian adolescents with virological suppression. HIV Med. 2017;18(4):235-44. https://doi.org/10.1111/hiv.12418.

21. Dimeglio LA, Wang JJ, Siberry GK, Miller TL, Geffner ME, Hazra $\mathrm{R}$, et al. Bone mineral density in children and adolescents with perinatal HIV infection. AIDS. 2013;27(2):211-20. https://doi. org/10.1097/QAD.0b013e32835a9b80.

22. Donà D, Mozzo E, Luise D, Lundin R, Padoan A, Rampon O, et al Impact of HIV-1 infection and antiretroviral therapy on bone homeostasis and mineral density in vertically infected patients. J Osteopos. 2019. https://doi.org/10.1155/2019/1279318.

23. Shiau S, Yin MT, Strehlau R, Patel F, Mbet N, Kuhn L, et al. Decreased bone turnover in HIV-infected children on antiretroviral therapy. Arch Osteoporos. 2018;13(1):40. https://doi.org/10.1007/s11657-018-0452-6.

24. Jacobson DL, Lindsey JC, Gordon CM, Moye J, Hardin DS, Mulligan K, et al. Total body and spinal bone mineral density across Tanner stage in perinatally HIV-infected and uninfected children and youth in PACTG 1045. AIDS. 2010;24(5):687-96. https://doi.org/10.1097/QAD.0b013e328336095d.

25. Rauchenzauner M, Schmid A, Heinz-Erian P, Kapelari K, Falkensammer G, Griesmacher A, et al. Sex- and age-specific reference curves for serum markers of bone turnover in healthy children from 2 months to 18 years. J Clin Endocrinol Metabol. 2007;92(2):443-9. https://doi.org/10.1210/jc.2006-1706. 